\title{
Public Expenditures, Growth and Distribution in a Mixed Regime of Education with a Status Motive*
}

\author{
Frederic Tournemaine ${ }^{\dagger}$ \\ University of the Thai Chamber of Commerce \\ Christopher Tsoukis \\ London Metropolitan University
}

\begin{abstract}
This paper tackles the issue of growth, distribution and the provision of public services in a growth model with human capital accumulation where heterogeneous individuals decide whether to attend a publicly funded education regime or a privately funded one. Heterogeneity of individuals is introduced via their statusmotivation which is shown to affect their choice of education. In such a framework, we obtain an inverted-U shaped relationship between growth and the size of the public education sector. In contrast with the general wisdom: we show that a larger public education sector is compatible with both a reduction of inequalities and an increase of long-term growth. Although we demonstrate that in a majoritarian system all individuals agree on a lower size of the public education regime than that which maximises growth, our analysis also highlights the tension between the direct beneficiaries and non-beneficiaries from the public regime.
\end{abstract}

JEL Classification: E10, O41, Z13.

Keywords: status, educational choice, growth, distribution.

${ }^{*}$ We would like to thank two anonymous referees, Nattavudh Powdthavee, Vasileios Zikos, the seminar participants at the workshop on The Political Economy of Development 2011, the Brunel Macroeconomic Research Centre and Quantitative and the Brunel Macroeconomic Research Centre (BMRC) and Quantitative and Qualitative Analysis in Social Sciences (QASS) Annual Conference 2010, primarily Sugata Ghosh, for their useful comments and suggestions.

$\dagger$ Address: School of Economics, University of the Thai Chamber of Commerce, 126/1 VibhavadeeRangsit Road, Dindaeng, Bangkok, 10400, Thailand. E-mail: frederic.tournemaine@gmail.com

$\ddagger$ Address: Dept. of Economics, London Metropolitan University, 84 Moorgate, London EC2M 6SQ, UK. E-mail: c.tsoukis@londonmet.ac.uk 


\section{Introduction}

The role of human capital in promoting growth and economic development is a longestablished theme since at least Lucas (1988). The main mechanism for supporting human capital is education; empirical evidence on this connection has been presented by a number of authors such as Barro (1991), Mankiw, Romer and Weil (1992). Besides fostering growth, education can reduce inequalities. In this respect, the government can play a crucial role, as it has been established by the early contributions of Schultz (1961, 1963, 1964). By providing free access to public education, the government allows those who would not have the necessary resources to invest in education otherwise, to acquire knowledge and skills. In other words, as education is uniformly provided, it smooths inequalities, and thus is egalitarian, as it has been theoretically and empirically shown by several authors such as Glomm and Ravikumar (1992), Saint-Paul and Verdier (1993), Zhang (1996), Gradstein and Justman (1997) and Sylwester (2002). The primary concern of these papers, however, is the analysis of the effect of different education alternatives such as public versus private education on subsequent inequality. Although the choice of educational system is endogenous and made via a majority voting system, the fact remains that, in these contributions, only one system of education prevails in equilibrium.

In the present paper, we seek to combine the hitherto rather separate strands of literature that investigate the effects of government expenditure on education on growth and distribution. Contrary to the papers cited above, our focus is on a mixed regime of education. Our point of departure is similar to Cardak (2004) and Chen (2005). Specifically, we argue that the structure of the educational system is an important determinant of the growth-inequality relationship which is itself a vexed issue not fully clarified in the literature. ${ }^{1}$ The role of public education in this relationship is pivotal. Given the importance of the issue, the likely multiplicity of mechanisms involved and the critical role of public education in this regard, it should be of value to develop alternative and complementary approaches to tackle the problem. In that sense, this paper brings forward the social status motive as an explanation for the education regime choice of individuals and investigates the choice of the size of public education under majority voting. As we will see, the 'status' channel can complement the one suggested by Cardak (2004) and Chen (2005) and can have different implications for the growth-inequality relationship. ${ }^{2}$

The social status motive has recently received considerable attention, as it has been recognised that, in addition to individual consumption postulated by standard theory, an agent's utility function may also depend on the individual's position in the distribution (see, e.g., Clark and Oswald, 1996; McBride, 2001; Choudhary et al., 2007; Maurer and Meier, 2008). It has been variously termed 'keeping up with the Joneses' or 'status-

\footnotetext{
${ }^{1}$ See, for instance, Tsoukis and Tournemaine (2012) for a discussion and more references on this issue and also footnote 18 .

2In Cardak's (2004) framework, those in private education experience growth via a standard linear mechanism, while in the public one they experience growth via a spillover effect. It is shown that heterogeneity in initial endowment of human capital results in a kind of polarization in income distribution. Chen (2005) focuses on credit market imperfections and the influence of financial development. He shows that, to reduce inequality, the government should induce individuals to attend public schools.
} 
seeking' (see, e.g., Abel, 1990; Corneo and Jeanne, 1997; Tournemaine and Tsoukis, 2008). It is by now widely thought that such motives may have important effects related to both growth and distribution (see, e.g., Futagami and Shibata, 1998; Corneo and Jeanne, 1999; Pham, 2005; Tournemaine and Tsoukis, 2010). Moreover, as shown by Alvarez-Cuadrado et al. (2004), such effects also impact the speed of convergence of an economy and the kind of response we can expect when a shock occurs.

In this paper, we argue that there is an important interplay between the choice of education regime and the structure of social interactions. ${ }^{3}$ In this vein, we concur with Bernal (2005) who explains that middle and upper social classes prefer to send their children to private education, while poorer populations including ethnic minorities and immigrants attend the public education sector for free. Similarly, Ball $(1993,1997)$ and Ball, Bower and Gewrirtz (1995) establish that the choice of education system in the US or UK can be interpreted as a way to maintain or even boost social status. In the same spirit, Anderson (1988) uses Australian data to show the importance of the connections between status, religious beliefs and choice of education regime.

To capture these features, we develop a model with human capital accumulation where heterogeneous individuals must choose between a publicly funded education system and a privately funded one. Heterogeneity across individuals is introduced via an idiosyncratic parameter measuring their status-motivation. Interestingly, although simple, our model is rich enough to allow the examination of a number of important and various issues, namely the relation between the size of the government and growth, the growth-inequality nexus and political economy issues. ${ }^{4}$

Our main results may indeed be summarised as follows. In contrast with Chen (2005) who finds a monotonic relationship between growth and the size of the public education system (defined here by the level of income tax rate), we obtain an inverted-U relationship. Thus, in contrast with Glomm and Ravikumar (1992), Saint-Paul and Verdier (1993), Zhang (1996), but in line with Gradstein and Justman (1997), we show that a higher level of growth and lower inequality can be mutually compatible when the government promotes public education. ${ }^{5}$ The rationale behind our result is similar to that in Barro (1990): Due to productive public services, higher government spending benefits growth when the economy is starved of such services; gradually, however, as diminishing returns set in, the tax-related disincentives from such policies begin to dominate. In investigating the growth-maximising tax rate, we find that its level depends on the contribution of

\footnotetext{
${ }^{3}$ The notion that 'status' considerations also affect the level of education of individuals has been investigated by Fershtman, Murphy and Weiss (1996) and Tournemaine and Tsoukis (2009). However, the idea of a choice between private and public education and its consequences on growth and distribution has been overlooked by this literature.

${ }^{4}$ Our framework can also be related to the literature on government versus private provision of public goods (see, e.g., Devarajan et al., 1998; Chatterjee and Morshed, 2011). An important difference of these frameworks with ours, though, is that they do not consider either the possibility of parallel investments (public-private) which may interact with each other, or the issue of distribution.

${ }^{5}$ De la Croix and Doepke (2004) also show that higher expenditures in public education promotes growth. In their framework, this outcome arises when inequality is high, and is due to a reduction in fertility differentials not formalised in this paper.
} 
education in the production function (in the spirit of Barro, 1990), but also on the relative size of the public- and private- education attending groups, as those affect the effective size of the education spillover.

Considering a model with heterogeneous individuals, however, allows us to depart significantly from a Barro-type analysis: we can indeed raise political economy issues. Thus, our framework can be related to the large literature initiated by Alesina and Rodrik (1994) which focuses on the distributive conflict between individuals and the resulting relationship between growth and inequalities. ${ }^{6}$ While Alesina and Rodrik (1994) point out the potential conflicts on the size of the public sector between capitalists and workers who benefit from public expenditures, in our framework the conflicts arise between the beneficiaries and non-beneficiaries from public education. Those who benefit from the public education system prefer a larger public sector (i.e. more tax), while those who attend the private education system prefer a smaller size. Furthermore, in a majority voting system whereby individuals vote for the size of the public education system, we show that all individuals agree on a tax level which is lower than the one which maximises growth. In light of this result, a corollary is that there is no trade-off between growth and equity, i.e. our framework shows that a higher level of growth and a lower level of inequality can be mutually compatible when the government promotes public education. We arrive at this conclusion from two angles: Because of the educational spillover, a more widely-shared education promotes growth; moreover, in the most plausible scenario, we are in the upward-sloping section of the tax-growth inverted U-shaped relation. ${ }^{7}$

The remainder of the paper is structured as follows. We introduce the model in Section 2. In Section 3, we derive and analyse the equilibrium properties of a mixed regime of education with respect to growth, distribution and the size of the public education system. We conclude in Section 4.

\section{Model}

We consider a closed economy in continuous time populated by a mass [0,1] of infinitelylived individuals. Time, denoted by $t$, goes from zero to infinity. We assume that there are two groups of identical individuals denoted by $k, k=1,2$, differentiated by their valuations of status in consumption (see below). Group 1 has a size $p$ and group 2 has a size $1-p$. Each individual is initially endowed with $T$ units of labour-time and $H_{k 0}>0$ units of human capital. Each individual engages in the production of an output, $Y_{k t}$, that can be consumed, $C_{k t}$, or allocated to fund schooling activities in order to acquire new units of human capital, $H_{k t}$.

There are two types of education: a public (publicly funded) one, and a private (privately funded) one. Everybody pays an income tax at rate $\tau>0$ which is used to fund

\footnotetext{
${ }^{6}$ See also the influencial work by Alesina and Tabellini (1990) on the choice of individuals with respect to the government's profile of public spendings.

${ }^{7}$ This finding shares some similarities with that of Benabou (2002) who, however, does not consider status motive as a source of inequality among individuals.
} 
public education. We assume that the budget constraint of the government is balanced at each moment, i.e. the amount spent in public education matches exactly the amount of funds collected at each moment (see below). All individuals can benefit from the public educational system. Individuals, however, who attend the private educational system must pay additional educational expenses in the form of a fraction of their income: $\varepsilon_{k t}>0$. It is worthwhile to mention that $\varepsilon_{k t}$ is a parameter of choice for individuals who are in private education, and who still pay the tax rate $\tau$. Obviously, $\varepsilon_{k t}=0$ for individuals who are in public education. Thereby, the level of human capital of people depends on their choice of education (private or public).

In what follows, we borrow the technology of public education set by Glomm and Ravikumar (1992). We implicitly assume that the level of human capital of individuals who opt for the publicly funded educational system evolves across time but is common across all participants in that system: $H_{k t}=H_{t}^{\text {pub }}$ for any individual in public education. In contrast, for individuals who are in the private educational system, the level of human capital is determined by the level of expenditures, $\varepsilon_{k t} Y_{k t}$. As we will see, the human capital obtained in private education is in general larger than that obtained under public education $\left(H_{k t}^{p r i}>H_{t}^{p u b}\right)$. This is an intuitive outcome: if this was not the case, individuals would never make additional expenditures on education (in addition to the tax that they pay regardless). Therefore, each individual has to solve two optimisation problems: maximising lifetime utility under each system (public/private), and choosing the one that gives them highest utility.

Following Saint-Paul and Verdier (1992), we assume that output is produced with a linear technology of the form: $Y_{k t}=A L_{k t} H_{k t}$, where $A>0$ is a productivity parameter and $L_{k t}$ is the labour-time an individual allocates to the production of output. ${ }^{8}$ The budget constraint of individual $k$ is given by

$$
C_{k t}=\left(1-\varepsilon_{k t}-\tau\right) A L_{k t} H_{k t},
$$

where $\varepsilon_{k t}=0$ if $H_{k t}=H_{t}^{p u b}$ and $\varepsilon_{k t}>0$ if $H_{k t}=H_{k t}^{p r i}$.

The individual technology of human capital in the public sector is given by

$$
\stackrel{\bullet}{H_{t}^{p u b}}=\phi \tau \overline{Y_{t}},
$$

where $\phi>0$ is a productivity parameter and $\overline{Y_{t}}$ is the geometric mean level of output in the economy. For technical simplicity, as in Abel (2005), throughout the paper we apply a standard geometric mean aggregation rule: $\overline{Y_{t}}=\left(Y_{1 t}\right)^{p}\left(Y_{2 t}\right)^{1-p} \cdot{ }^{9}$

The law of motion of individual human capital in the private education sector is given by:

$$
\stackrel{\bullet}{H_{k t}^{p r i}}=\phi\left(\varepsilon_{k t} Y_{k t}\right)^{1-\varphi}\left(\overline{H_{t}}\right)^{\varphi},
$$

\footnotetext{
${ }^{8}$ Like Saint-Paul and Verdier (1992), we do not incorporate physical capital in the production function. Adding physical capital would complicate, but not "wash away", the effects we are discussing here.

${ }^{9} \mathrm{An}$ arithmetic average of the form $\overline{Y_{t}}=p Y_{1 t}+(1-p) Y_{2 t}$ would complicate the analysis without altering the results we derive here.
} 
where $0<\varphi<1$ is the weight of existing human capital, $\overline{H_{t}}=\left(H_{1 t}\right)^{p}\left(H_{2 t}\right)^{1-p}$, relative to material resources (degree of spillover effect).

Comments are in order here. Firstly, in production function (2), we postulate that individual human capital produced in the public education regime accumulates depending on the geometric mean income, $\overline{Y_{t}}$. This specification allows us to account implicitly for a spillover effect of human capital which acts through $\overline{Y_{t}}$, and also to avoid a spurious scale effect whereby a bigger economy (with the same structure) would accumulate human capital faster.

Introducing spillover effects in the form of mean human capital as implicitly specified in (2) and explicitly in (3), is common in the growth literature. An additional reason to introduce such spillover effects is that they are shown to be crucial for human capital convergence (Tamura, 1991; de la Croix and Doepke, 2004) and have empirical support (Alonso-Carrera, 2001). Observe that it would be possible to specify a more general technology of education in the public sector, such as: $\stackrel{\bullet}{H_{t}^{p u b}}=\phi\left(\tau \overline{Y_{t}}\right)^{1-\varphi}\left(\overline{H_{t}}\right)^{\varphi}$. Though this formalisation appears as the counterpart of (3) as individuals get a kind of share of average output (this share being determined by the level of the tax rate, $\tau$ ), it would complicate the analysis without modifying our main results. Intuitively, as output is linear with respect to human capital $\left(Y_{k t}=A L_{k t} H_{k t}\right)$, at the aggregate level, $\overline{Y_{t}}$ necessarily depends linearly on mean education $\overline{H_{t}}$. Thus, technology (2) is used for tractability and must be taken as a short-cut. ${ }^{10}$

Finally, there is no labour in the production function of either type of education. ${ }^{11}$ Such human capital technology has been used and discussed by de la Croix and Michel (2002, see e.g. chapter 5) among others. The main idea is that the existence of teachers is only implicitly assumed, but they are not explicitly modelled. That is, the standard trade-off which occurs between output production (consumption) and education in the case of a model where labour-time is an input of the human capital accumulation process, is here (directly) taken into account via the fraction of resources devoted to education.

Preferences of any individual $k$ are represented by,

$$
U_{k t}=\int_{0}^{\infty}\left[\log \left(C_{k t}\right)+\delta_{k} \log \left(C_{k t} / \overline{C_{t}}\right)+\eta\left(T-L_{k t}\right)\right] e^{-\rho t} d t
$$

where $\rho>0$ is the rate of time preference, $\eta>0$ denotes the constant-marginal disutility of work and $\delta_{k} \log \left(C_{k t} / \overline{C_{t}}\right)$ represents the preference of an individual regarding social status, where the geometric mean $\overline{C_{t}}=\left(C_{1 t}\right)^{p}\left(C_{2 t}\right)^{1-p}$ is taken as given. ${ }^{12}$ A notable feature in (4) is that the "status function" is specific to the individual $k$, i.e. the functional form of the status function (not only the argument inside) differs between individuals. Throughout

\footnotetext{
${ }^{10} \mathrm{~A}$ formal proof that such a change would not affect the main results is given in the appendix.

${ }^{11} \mathrm{~A}$ similar formalisation is also widely used in the R\&D-based literature where the amount of material resources taken from the final output often replaces the quantity of labor devoted to research. See for instance Jones and Williams (1998, 2000).

${ }^{12}$ Tsoukis (2007) discusses the possibilities for modelling the status function, but here the "multiplicative" formulation (individual as a ratio over average consumption) is assumed for tractability.
} 
the paper, we assume that $\delta_{1}<\delta_{2}$ to capture the notion that individuals of group 2 are more motivated for status, or antagonistic, or rivalrous than individuals of group 1.

Although, there exist other ways to formalise social status, it is important to mention that none of the results we derive hinge on our particular specification. As we will see, the status in consumption induces the more motivated individuals to work more and thus to accumulate more human capital. This is the same effect as the one we would obtain in a model where status is defined as: (i) the relative level of human capital of an individual to that of others (see, e.g., Fershtman, Murphy and Weiss, 1996; Tsoukis and Tournemaine, 2009 ); or (ii) the relative amount of wealth (physical capital) of an individual to that of others (see, e.g., Corneo and Jeanne, 1997 and 1999; Pham, 2005, Tournemaine, 2008).

\section{Equilibrium}

In this section, we solve two optimisation problems, for the typical individual in public education and private education, respectively. Then, we determine which type of educational regime each individual chooses. To avoid complexity, we investigate the steady-state outcome and relegate the analysis of the transitional dynamics in Appendix 5.4. The analysis of the transitional dynamics shows that the equilibrium is a saddle point which is stable around the steady state.

To proceed, we assume that agents build status-seeking in consumption, as analysed, into their optimality conditions, taking the geometric means as given. In doing so, they are also assumed to be able to accurately forecast the relevant aggregate statistics (mean consumption) one instant ahead. ${ }^{13}$ The outcome of this process is a Nash equilibrium, whereby agents respond optimally to aggregate outcomes and, in so doing, reproduce them (or the distributions from which aggregate statistics are drawn). The assumption of an (infinitesimal) lag between the time on which information is based and the realisation of outcomes allows us to avoid explicit game-theoretic considerations (that is, following Pollack, 1976, p. 310; and the "catching up" model of Abel, 1990).

\subsection{Public education}

If an individual participates in public education, she gets the standard education output: $H_{t}^{p u b}$. Thus, the problem of such individual reduces to the choice of consumption, $C_{k t}$, and labour-time devoted to output production, $L_{k t}$, that maximise (4) subject to the budget constraint given by (1) where $\varepsilon_{k t}=0$. After some manipulation, we obtain: ${ }^{14}$

$$
\eta=\frac{1+\delta_{k}}{L_{k}}
$$

\footnotetext{
${ }^{13}$ This is the assumption of "rational myopic foresight", which is a standard hypothesis in macroeconomics, see, e.g., Turnovsky, (1996, Ch. 3) for more discussion.

${ }^{14}$ Throughout the paper, we use the usual convention of dropping the index of time for constant variables in steady state.
} 
Equation (5) says that the marginal benefit of an additional unit of labour allocated to the production of good equals its marginal cost in utility terms. The marginal benefit comprises two components: the direct benefit from an additional unit of consumption plus the indirect gain due to the improvement in social status, $\delta_{k}$.

For future reference, we compute the growth rate of human capital attainable in public education. From equation (2), we obtain:

$$
g^{p u b}=\phi \tau \frac{\overline{Y_{t}}}{H_{t}^{p u b}} .
$$

\subsection{Private education}

Individuals who are in the private education regime choose consumption, $C_{k t}$, labour-time spent in output production, $L_{k t}$, but also the share of income to devote to education, $\varepsilon_{k t}$, and the path for human capital, $H_{k t}$. The current value Hamiltonian of this problem is: $C V H_{k t}=\log \left[\left(C_{k t}\right)\left(C_{k t} \overline{C_{t}}\right)^{\delta_{k}}\right]+\eta\left(T-L_{k t}\right)+\mu_{k t} \phi\left(\varepsilon_{k t} A L_{k t} H_{k t}\right)^{1-\varphi}\left(\overline{H_{t}}\right)^{\varphi}$, where $\mu_{k t}$ is the co-state variable associated to the law of motion of human capital (3) and $C_{k t}=$ $\left(1-\varepsilon_{k t}-\tau\right) A L_{k t} H_{k t}$ (see (1)). The first order conditions are:

$$
\begin{gathered}
\frac{\partial C V H_{k t}}{\partial L_{k t}}=\frac{1+\delta_{k}}{L_{k t}}-\eta+\mu_{k t}(1-\varphi) \frac{\dot{H}_{k t}^{p r i}}{L_{k t}}=0, \\
\frac{\partial C V H_{k t}}{\partial \varepsilon_{k t}}=-\frac{\left(1+\delta_{k}\right)}{\left(1-\varepsilon_{k t}-\tau\right)}+\mu_{k t}(1-\varphi) \frac{\dot{H}_{k t}^{p r i}}{\varepsilon_{k t}}=0, \\
\frac{\partial C V H_{k t}}{\partial H_{k t}}=\frac{\left(1+\delta_{k}\right)}{H_{k t}}+\mu_{k t}(1-\varphi) \frac{\dot{H}_{k t}^{p r i}}{H_{k t}}=-\dot{\mu}_{k t}+\rho \mu_{k t} .
\end{gathered}
$$

The transversality condition is: $\lim _{t \rightarrow \infty} \mu_{k t} H_{k t} e^{-\rho t}=0$.

Under the assumption that the economy is in steady state, we have $L_{k t}=L_{k}, \varepsilon_{k t}=\varepsilon_{k}$ and $\dot{\mu_{k t}} / \mu_{k t}+\stackrel{\bullet}{H_{k t}^{p r i}} / H_{k t}=0$ at each instant. Using this information, simple manipulations of the first order conditions yield:

$$
\begin{gathered}
\frac{1+\delta_{k}}{L_{k}} \frac{1-\tau}{1-\tau-\varepsilon_{k}}=\eta \\
\frac{1-\tau-\varepsilon_{k}}{\varepsilon_{k}}=\frac{\varphi g_{k}^{p r i}+\rho}{(1-\varphi) g_{k}^{p r i}}
\end{gathered}
$$

and, from equation (3), the growth rate of human capital of individual $k$ in private education is:

$$
g_{k}^{p r i}=\phi\left(\varepsilon_{k} A L_{k}\right)^{1-\varphi}\left(\frac{\overline{H_{t}}}{H_{k t}}\right)^{\varphi} .
$$


In analogy with the problem under public education, equation (7) states that the marginal benefit of an additional unit of labour allocated to the production of the consumption good equals its marginal cost in utility terms on the right hand side. We note that (7) coincides with (5) for $\varepsilon_{k}=0$. The main difference between the two problems comes from an additional equilibrium condition under private education (equation (8)) and the level of the growth rate (equation (9)). The reason is that in the problem under public education, individuals take the path of education as given. In contrast, under the private educational system individuals take an active part in the formation of their own level of education. Such a choice is summarised by equation (8) which is the outcome between the Euler condition determining the path of accumulation of human capital and the choice of investments in private education, $\varepsilon_{k}>0$.

\subsection{Choice of education regime}

Having set out the optimisation of each type of individual conditional on the choice of the education regime, we now determine what type of education an individual chooses in the first place. Under the assumption that the economy is in steady state, an important property is that the level of the growth rates must be common across individuals: we have $g^{p r i}=g^{p u b}=g$ for all individuals. This outcome results from the presence of the human capital spillover, $\overline{H_{t}}$, in the technology of production of human capital (2) and (3): This implies that, as the level of human capital in private education forges ahead of the average, it acts to slow down its growth rate. As said before, this is likely to bring a convergence of human capital to common growth rates, as found in the literature (see Section 2).

Given that we have two types of individual $\left(\delta_{1}\right.$ and $\left.\delta_{2}\right)$, to determine their choice of education regime, it is convenient, first, to characterise the threshold level of ambition, labelled hereafter by $\widetilde{\delta}$, of a "marginal" or "cutoff" individual, i.e. one who would be indifferent between public and private education. The main characteristic of this individual is that his/her long-run level of welfare is the same in both regimes of education. To be consistent with our assumptions, we assume that $\widetilde{\delta}$ is such that a share $p$ of individuals opts for the public education regime while the remaining share $1-p$ attends the private regime. ${ }^{15}$ In that sense, comparing the actual level of ambition of an individual $k$, given by $\delta_{k}, k=1,2$, to $\widetilde{\delta}$, we will be able to determine which type of education an individual chooses. To proceed, we assume that the choice of education regime is made once and for all at the beginning of the planning horizon $(t=0)$ for all individuals; this presupposes perfect foresight, an assumption in line with the deterministic nature of our model. Specifically, using the utility function (4), straightforward manipulations show that the marginal individual with ambition $\widetilde{\delta}$ verifies

$$
\int_{0}^{\infty}\left[(1+\widetilde{\delta}) \log \left(\frac{\widetilde{C}_{t}^{p r i}}{\widetilde{C}_{t}^{p u b}}\right)-\eta\left(\widetilde{L}^{p r i}-\widetilde{L}^{p u b}\right)\right] e^{-\rho t} d t=0
$$

\footnotetext{
${ }^{15}$ The details of computing the exact value of $\widetilde{\delta}$ are provided in Appendix 5.1.
} 
where $\widetilde{L}^{p r i}$ and $\widetilde{L}^{p u b}$ denote the labour supply of the marginal individual in each regime of education, and symmetrically $\widetilde{C}_{t}^{p r i}$ and $\widetilde{C}_{t}^{p u b}$ denote her level of consumption. Equation (10) captures the two effects of the long run: consumption considerations favour private education because the labour supply and human capital are higher in that regime; but leisure considerations in utility favour public education because under that regime the individual works less. Had equation (10) been greater (lower) than zero, the utility from private (public) education would be greater.

As shown in Appendix 5.1, the model-economy described in Section 2 admits the existence of a unique (saddle) steady state in which individuals face a common rate of growth $g$ and choose in an endogenous manner the kind of educational regime to attend. The choice of education regime depends on the individuals' level of motivation, $\delta_{k}, k=1,2$, relative to the level of motivation $\widetilde{\delta}$. As our model-economy comprises two types of individuals, the following Proposition applies:

\section{Proposition 1: On the individuals' choice of education regime:}

Under the assumption that the government levies a flat tax rate $\tau>0$ on income, there exists a unique level of ambition, $\widetilde{\delta}$, so that the individual with ambition $\widetilde{\delta}$ is exactly indifferent between public and private education. Thus, as $\delta_{1}<\delta_{2}$, we have:

(a) If $\delta_{1}<\delta_{2}<\widetilde{\delta}$, every individual opts for the public education regime;

(b) If $\widetilde{\delta}<\delta_{1}<\delta_{2}$, every individual opts for the private education regime;

(c) If $\delta_{1}<\widetilde{\delta}<\delta_{2}$, individuals of group 1 opt for public education while individuals of group 2 opt for private education.

Proof: See Appendix 5.1.

Proposition 1 establishes which type of individual chooses (in an endogenous manner) which type of education to attend. Cases (a) and (b) represent corner solutions whereby all individuals opt for the same educational regime while case (c) represents a mixed regime of education where both public and private education co-exist. In the remainder of the paper, we restrict our attention to the mixed regime of education (c). The results we obtain in a pure public regime (a) and in a pure private regime (b) as well as their comparison are relegated to Appendix 5.3.

\subsection{Growth and distribution in the mixed regime of education}

\subsubsection{Steady state}

In this sub-section, we establish the steady-state outcome of the model in a mixed regime of education. We assume that $\delta_{1}<\widetilde{\delta}<\delta_{2}$. As shown in Appendix, we can manipulate equations (1), (2), (3), (5), (7), (8) to obtain the results depicted in Proposition 2 where the symbol "*" is used to denote any steady-state value.

Proposition 2: On the steady state in the mixed regime of education:

The mixed regime of education is characterized by constant amounts of labour allocated 
to output production:

$$
\begin{gathered}
L_{1}^{*}=\frac{1+\delta_{1}}{\eta} \\
L_{2}^{*}=\frac{1+\delta_{2}}{\eta}\left[\frac{\rho+g^{*}}{\varphi g^{*}+\rho}\right] .
\end{gathered}
$$

The expenditure ratio in private education is:

$$
\varepsilon^{*}=\frac{(1-\tau)(1-\varphi) g^{*}}{g^{*}+\rho} .
$$

The common rate of growth, $g^{*}$, is the solution of:

$$
\begin{aligned}
& \frac{g^{1+\frac{(1-p)}{p}}(\varphi g+\rho)^{(1-p) \frac{p \varphi+1-\varphi}{p \varphi}}}{(\rho+g)^{(1-p)}} \\
= & \phi^{1+\frac{(1-p)}{p \varphi}}\left(\frac{A}{\eta}\right)^{1+\frac{(1-p)(1-\varphi)}{p \varphi}}\left(1+\delta_{1}\right)^{p}\left(1+\delta_{2}\right)^{(1-p)\left(1+\frac{(1-\varphi)}{p \varphi}\right)} \tau[(1-\tau)(1-\varphi)]^{\frac{(1-p)(1-\varphi)}{p \varphi}} .
\end{aligned}
$$

The relative amount of human capital, $\widehat{H}^{*} \equiv\left(H_{1 t} / H_{2 t}\right)^{*}$, and consumption, $\widehat{C}^{*} \equiv\left(C_{1 t} / C_{2 t}\right)^{*}$, are given by:

$$
\begin{gathered}
\widehat{H}^{*}=\left[\frac{\phi A\left(1+\delta_{1}\right)^{p}\left(1+\delta_{2}\right)^{(1-p)}}{\eta}\right]^{\frac{1}{1-p}}\left(\frac{\tau}{g^{*}}\right)^{\frac{1}{1-p}} \frac{\rho+g^{*}}{\varphi g^{*}+\rho}<1, \\
\widehat{C}^{*}=\frac{1+\delta_{1}}{1+\delta_{2}} \widehat{H}^{*}<1,
\end{gathered}
$$

Proof: See Appendix 5.2.

Direct inspection of Proposition 2 allows us to establish the main properties of the model in a mixed regime of education with respect to growth and distribution. We note from equations (11) and (12) that the labour supply of individuals attending private education is higher than that of those attending public education for two reasons: not only is there a kind of structural break due to the change in educational regime which leads individuals to allocate more resources to output production, but also those in private education are the more motivated: $\delta_{2}>\delta_{1}$.

Thereby, status-seeking is an adequate source of heterogeneity: even if the only source of heterogeneity is the idiosyncratic pursuit of status, this is enough to generate real heterogeneity among individuals, with different labour supplies, and different choices of education. This result is important as the very status-seeking motive also generates the asymmetry that gives scope to status-seeking. Thus, heterogeneity is entirely due to subjective, rather than objective, reasons (such as skills or endowments heterogeneity). Equations (15)-(16) reveal indeed that individuals 1, who are less motivated, end up with 
a lower level of human capital, $\widehat{H}^{*}<1$, and consumption, $\widehat{C}^{*}<1$. For the latter, statusrelated motivation matters in a dual way, both because of the differences in work effort (the first ratio), but also because of differences in acquired human capital (second ratio). ${ }^{16}$ As a result, inequalities in consumption are greater than inequalities in human capital.

\subsubsection{The growth-inequality relationship}

In this sub-section, we spell out the implications of the model for growth and discuss the relationship between growth and distribution. Like Barro (1990), we can highlight the fundamental tension between the productive role of government services that is beneficial for growth and the distortionary role of the resulting taxation that is detrimental to growth. ${ }^{17}$ In our framework, this tension is reinforced because the government sector supports public education, which contributes to growth because of educational spillovers, but also provides a drag to growth as it takes resources away from individuals who will not use public education. To see this, from equation (14), we can compute:

$$
\frac{d g^{*}}{d \tau}=\left[\frac{1}{\tau}-\frac{(1-p)(1-\varphi)}{p \varphi(1-\tau)}\right]\left\{\left[\frac{1}{(1-p)}+\frac{1}{p}\right] \frac{(\rho+g)}{g}+\frac{(p \varphi+1-\varphi)(\rho+g)}{p(\varphi g+\rho)}\right\}^{-1} \text {. }
$$

The first term in brackets on the right hand side of $(17), 1 / \tau$, represents the positive effect of public education, which contributes to growth via the spillover effect; the second term in brackets on the right hand side, $(1-p)(1-\varphi) /[p \varphi(1-\tau)]$, is the resourcewithdrawal effect that the tax exerts on private education, which is detrimental for growth. Hence, there is an inverted U-shaped relationship between growth and the size of the public educational sector. Formally, maximum growth is attained if:

$$
\tau^{\max }=\frac{p \varphi}{(1-p)(1-\varphi)+p \varphi} .
$$

Thus, we can state:

Proposition 3: On the relationship between the size of the public education sector and growth in a mixed regime of education:

If $\tau<\tau^{\max }\left(\tau>\tau^{\max }\right)$, a larger public education sector increases (decreases) growth.

The growth-maximising tax rate reflects two factors. On the one hand, it reflects the contribution of public services to the production of private education through the spillover effect, $\varphi$. As a result, the tax-maximising growth rate is increasing with $\varphi\left(d \tau^{\max } / d \varphi>0\right)$ : larger spillovers from public education are indeed synonymous with a greater contribution of public education to the determination of the long-run level of growth. Moreover, it

\footnotetext{
${ }^{16}$ In a pure private regime, the same kind of result would apply: $\widehat{H}^{*}<1, \widehat{C}^{*}<1$. In a pure public regime, however, we would obtain $\widehat{H}^{*}=1$, but as before we would obtain $\widehat{C}^{*}<1$ due to a lower labour supply in output production from individuals 1 (see Appendix 5.3).

${ }^{17}$ See Futagami, Morita and Shibata, (1993), Ghosh and Mourmouras (2004), Tsoukis and Miller (2003) for further references on this issue.
} 
reflects the relative size of each sector, so that the "technical spillover" is also weighted by the size of the group in public education, $p$. Ceteris paribus, the greater is the number of people attending public education, the higher the growth-maximising tax rate should be: $d \tau^{\max } / d p>0$. Thus, our analysis adds to the analysis of growth-maximising flat income-tax rate, that has focused so far on the technical contribution of public services, the size of the sector that utilises such services.

Our analysis also highlights the tension between the direct beneficiaries and nonbeneficiaries from such services, absent in an explicit way from the original $A K$ framework of Barro (1990). This raises political economy issues, absent in earlier analyses, which are analysed in the next Section. Before turning to this issue, it is interesting to analyse the effects of a change in the tax rate on inequality. From equations (15) and (16), noting that $1-\left(\tau / g^{*}\right) d g^{*} / d \tau>0$ (see $\left.(17)\right)$ and given that $0<1-g^{*}(1-p)(1-\varphi) \rho /\{(\rho+$ $\left.\left.g^{*}\right)\left(\varphi g^{*}+\rho\right)\right\}<1$ is always satisfied, we obtain

$$
\begin{gathered}
\frac{d \widehat{H}^{*}}{d \tau}=\frac{\widehat{H}^{*}}{(1-p) \tau}\left\{1-\frac{\tau}{g} \frac{d g^{*}}{d \tau}\left[1-\frac{g^{*}(1-p)(1-\varphi) \rho}{\left(\rho+g^{*}\right)\left(\varphi g^{*}+\rho\right)}\right]\right\}>0, \\
\frac{d \widehat{C}^{*}}{d \tau}=\left(\frac{1+\delta_{1}}{1+\delta_{2}}\right) \frac{d \widehat{H}^{*}}{d \tau}>0 .
\end{gathered}
$$

Equations (19) and (20) reveal that, in a mixed regime of education, inequalities in the level of education and consumption decrease as the size of the public education sector increases if it is sufficiently small $\left(\tau<\tau^{\max }\right) .{ }^{18}$ Thus, we can state:

Proposition 4: On the relationship between the size of the public education system, growth and inequality in the mixed regime:

Since a larger public education regime always reduces inequalities, higher growth and more equity are compatible as long as $\tau<\tau^{\max }$.

Glomm and Ravikumar (1992) and Saint-Paul and Verdier (1993) also show that an increase in the size of the public education sector reduces inequality and increases growth. The crucial difference with our paper, however, is that their result is obtained in a pure public education regime. That is, while the positive correlation between the size of the government and economic growth in a pure public education regime seems intuitive, such conclusion is not as obvious in a mixed regime of education. A greater amount of resources devoted to public education means in effect a greater relative cost of investments in private education as it takes (almost mechanically) away resources (from the more motivated individuals) which could have been invested in private education.

\footnotetext{
${ }^{18}$ From a general perspective, one should mention that at the empirical level, the issue of whether inequality and growth are positively or negatively correlated remains open. Persson and Tabellini (1994) present cross-country evidence of a negative effect of inequality on growth. In contrast, using a panel of US states, Partridge (1997) concludes that greater inequality is associated with greater growth. Other studies, finally, conclude that changes in income and changes in inequality are unrelated (Deninger and Squire, 1996; Chen and Ravallion, 1997). At a theoretical level, we can refer to Aghion, Caroli and Garcia Penalosa (1999) who present a review of a variety of theoretical arguments on this issue.
} 
Therefore, this has a negative impact on investments in human capital accumulation in the private education sector (see equation (13)) and may be growth reducing. The reason why higher growth and lower inequality are compatible in our model is that, in the case where the tax rate is low $\left(\tau<\tau^{\text {max }}\right)$, the productivity of additional resources devoted to public education offsets the negative impact of lower resources devoted to private education: the economy is on the upward part of the inverted-U relationship describing growth against the tax rate. Note that, interestingly, in this case, the more motivated individuals compensate the increase in the size of the public sector by a greater amount of labour devoted to output production (see equation (12)). When the tax rate is high, in contrast, $\left(\tau>\tau^{\max }\right)$, the productivity gains in the public education sector are too small to compensate the reduction in resources devoted to the private educational sector. This has a negative impact on growth and on the labour supply of the more motivated individuals. We will see below that this latter case is, however, unlikely to occur in a democratic system where the size of the government is made by a median voter.

Before turning to this issue, it is interesting to relate the result of Proposition 3 and 4 to actual data. First of all, we can refer to the concluding remarks of Saint-Paul and Verdier (1993) who note that Western countries have enjoyed sustained growth associated with an evening of inequalities in the last two centuries. Taking France as an example, they explain that the promotion of public education contributed to such a trend. Similarly, the World Bank (1993) and Vandycke (2001) report more recent evidence from Asian countries in which government played an active role in the process of human capital accumulation. They argue that in promoting public education and in guaranteeing public education for all, the governments of these countries contributed to the rise in skills of their populations, leading in turn to the high levels of growth observed during the period 1965-1990 and a reduction in inequalities. More recently, Blankenau et al. (2007) validated this outcome using panel data from 23 developed countries over the period 1960-2000.

However, the fact remains that we can observe large disparities across countries with respect to the amount of resources spent in education. Data of OECD (2008) shows that there is a variety of public-private education mixes across countries. More precisely, OECD countries spend on average 5.8 percent of their GDP in education, with 84.7 percent coming from public sources and the remaining share coming from private sources. Some countries have public education shares well above ninety percent, sometimes very close to hundred percent such as Norway, Finland, Italy, France. In contrast, a number of countries put a larger responsibility on the private education system like in Japan, South Korea, UK, US and Canada among others. These large differences raise implicitly the issue concerning the choice of the government size, i.e. the actual choice of the tax rate, $\tau$. This task is carried out next.

\subsubsection{Equilibrium in a majority voting system: choice of public education size}

In this sub-section, we determine the choice of tax rate by the median voter, that is the amount of resources to be devoted to public education in a democratic system. To 
tackle this issue, we assume the existence of a majority voting system which allows the government to determine the level of the income tax-rate, $\tau$. To conduct the analysis, we assume that the economy has reached the steady state. In this case, we compute the long-run level of utility of individuals, i.e. when the labour supply of individuals 2 is constant and the growth rate of consumption equals the growth rate of human capital and the economy-wide growth rate, $g^{*}$. From (4) we obtain:

$$
U_{k 0}=-\frac{\delta_{k} \log \left(\overline{C_{0}}\right)}{\rho}+\left(1+\delta_{k}\right) \frac{\log \left(C_{k 0}\right)}{\rho}+\frac{\eta\left(T-L_{k}^{*}\right)}{\rho}+\frac{g^{*}}{\rho^{2}},
$$

where we recall that $\overline{C_{0}}=\left(C_{10}\right)^{p}\left(C_{20}\right)^{1-p}, C_{10}=(1-\tau) A L_{1}^{*} H_{10}, C_{20}=\left(1-\varepsilon^{*}-\tau\right) A L_{2}^{*} H_{20}$ and the labour supplies are given by equations (11) and (12).

We denote by $\tau_{k}, k=1,2$, the income tax rate chosen by a median voter belonging to group $k$. Under the assumption that the parameters of the model verify $\rho^{2}\left(1+\delta_{2}\right)(1-$ $\varphi) /\left(\varphi g^{*}+\rho\right)^{2}<1$, (which is verified if $\delta_{2}$ is small enough), the following applies:

Proposition 5: On the level of the tax rate in the mixed regime of education:

In a mixed regime of education, the median voter, and the democratic system in general, set a tax rate which is less than the growth-maximising one, $\tau^{\max }$. Formally, we have:

$$
\tau_{2}<\tau_{1}<\tau^{\max }
$$

where

$$
\begin{gathered}
\tau_{1}=\frac{\tau^{\max }}{\frac{\rho\left(1+\delta_{1}\right)(1-p)}{p \varphi+(1-p)(1-\varphi)}\left\{\left[1+\frac{\varphi p}{(1-p)}\right] \frac{1}{g^{*}}+\frac{(1-\varphi) \varphi}{\left(\varphi g^{*}+\rho\right)}\right\}+1}, \\
\tau_{2}=\frac{\tau^{\max }}{\frac{\rho\left(1+\delta_{2}\right)(1-p)\left\{\left[1+\frac{\varphi p}{(1-p)}\right] \frac{1}{g^{*}}+\frac{(1-\varphi) \varphi}{\left(\varphi g^{*}+\rho\right)}\right\}}{\left\{\left[1-\frac{\left(1+\delta_{2}\right)(1-\varphi) \rho^{2}}{\left(\varphi g^{*}+\rho\right)^{2}}\right][p \varphi+(1-\varphi)(1-p)]\right\}}+1} .
\end{gathered}
$$

Proof: Simple algebra applied to equation (21) in which we set $k=1$ and $k=2$, and where $\overline{C_{0}}$ is taken as given, allows us to obtain $\tau_{1}$ and $\tau_{2}$, respectively. Simple comparisons of the level of the different tax rates yield (22).

Proposition 5 has several implications. Interestingly, it states that individuals prefer a lower level of growth and a less equal society than those which are potentially possible to achieve (under $\tau=\tau^{\max }$ ). This result contrasts with the one obtained by Alesina and Rodrik (1994). They find that in general the median voter chooses a tax rate which is higher than the growth maximizing tax rate.

In fact there is one similarity and one difference between our result and that of Alesina and Rodrik (1994). The similarity is that in both frameworks, in choosing the tax rate level $\left(\tau_{k}, k=1,2\right)$, individuals balance the welfare losses (gains) in consumption from a larger public sector and the gains (losses) resulting from a higher (lower) level of growth. By construction, the growth maximising tax rate does not account for the (negative) impact that a larger public sector has on consumption. In the framework of Alesina and 
Rodrik (1994), the marginal benefit of a greater amount of public good (i.e. a greater tax rate) increases as the median voter becomes poorer, inducing individuals to choose a lower growth and a more equal society. In our model, in contrast, the mechanism at work is different. A greater size of the government is synonymous with a welfare loss in that individuals must sacrifice current consumption to fund the public education sector. This means that individuals prefer a lower level of growth, but now they also implicitly prefer and choose more inequality.

As $\tau_{1}$ is chosen by those who use the public education system and $\tau_{2}$ is chosen by those who attend the private education system, it follows that $\tau_{2}<\tau_{1}<\tau^{\max }$. The important feature is that, as we are likely to observe $\tau<\tau^{\max }$ in a democratic system, we have a possible explanation for the empirical fact discussed above whereby there seems to be a positive relationship between government expenditure in education and the level of economic growth. We thus can state:

Corollary 1: In democracies, we are likely to observe positively-correlated growth and equality rates.

Another interesting result is that individuals who attend the private education system are willing to allocate part of their income to educate the less motivated: we have $\tau_{2}>$ 0 . This result is not the outcome of an altruistic behaviour. This is due to the fact that the more motivated benefit indirectly from the public education system through the spillover effect, $\varphi$. In other words, the external effect is partly internalised by the more motivated individuals as they realise the positive effect on long-term growth of funding public education for the less ambitious (productive) ones.

We conclude with the implications of our analysis for societal welfare. Clearly, if the tax rate is below (above) the preferred rates of both groups, i.e. $\tau<\tau_{2}\left(\tau_{1}<\tau<\tau^{\max }\right.$ ), more public education increases growth, reduces inequalities and increases (decreases) the welfare of all individuals. In either of these cases, the policy prescription is clear: the tax rate should be changed in the direction that increases societal welfare. In the latter case, more specifically, the tax rate should be reduced, both decreasing the growth rate and increasing inequality; but that would increase societal welfare for the reasons given above. If, however, $\tau_{2}<\tau<\tau_{1}$, i.e. the tax rate is between the preferred rates of the two groups, a rise in the tax rate will only benefit the less motivated, while the welfare of the more motivated will decline. This conflict stems from the fact that the latter group helps finance public education from which they do not benefit except indirectly (via the educational spillover).

Viewed from an opposite angle, this implies that no group has an incentive to set a tax rate that maximises societal welfare given by, at date zero, $W_{0}=p U_{10}+(1-p) U_{20}$ (see (21)). Since, $\tau_{k}=\arg \max U_{k 0}, k=1,2$, it follows that $\tau_{2}<\tau_{w}<\tau_{1}$, where $\tau_{w}=\arg \max W_{0}$. Thus, the preferences of the two groups differ, on either side of the maximum welfare, but none has an incentive to vote for it. Furthermore, if we assume that the less motivated group is more numerous $(0.5<p<1)$ to capture the stylised fact of a right-skewed motivation (and therefore income) distribution, we conclude that the chosen tax-rate is given by $\tau_{1}$ and verifies $\tau_{1}>\tau_{w}$ : The actual tax rate is greater than 
the one maximising societal welfare. We can formalise this in the following Corollary:

Corollary 2: On the relation between actual and societal welfare maximizing tax rates:

Under majority voting and a right-skewed motivation distribution $(0.5<p<1)$, the actual tax rate is greater than the welfare maxisising one: $\tau_{w}<\tau_{1}$.

\section{Conclusion}

We conclude by the scope that our analysis gives. The choice between public and private education analysed here may be thought of as a parable for the provision of public goods in general, so that the results derived here may have a broader appeal. In particular, we may think of the public provision of health as another possible channel for the government to improve equity and boost growth. Health represents indeed an important component of human capital: a feature firstly recognised by Grossman (1972) in his seminal paper on demand for health and introduced in an endogenous growth model by van Zon and Muysken (2001). On the empirical side, authors such as Weil (2005) have provided evidence supporting the idea that health affects productivity both directly (healthier individuals make better workers) and indirectly (healthier individuals acquire more skills). Thus, health affects growth in quite a similar way as education does, and can be formalised in a similar way as in equations (2) and (3) (for public and private health). Therefore, our framework readily applies to health, too. Another interesting issue would be to endogenise the threshold value of status motive which separates individuals between private and public education regimes. The framework developed here is suitable for studying both these questions which are on the agenda for future work. 


\section{Appendix}

\subsection{Choice of education of individuals: proof of Proposition 1}

We characterise the choice of individuals regarding the education regime. First, we demonstrate the existence and uniqueness of the level of ambition $\widetilde{\delta}$ making an individual indifferent between the two regimes of education. Then, comparing the level of ambition of any individual to this critical level, we determine her choice of education. To get there, we assume that all individuals share the same level of ambition $\widetilde{\delta}$ with a share $p$ choosing the public regime and a share $1-p$ choosing the private regime.

Using (1), (5) and (8), with $\varepsilon=0$ when individuals are in public education and $\varepsilon>0$ when they are in private education, we can simplify (10) to obtain:

$$
\log \frac{H_{t}^{p r i}}{H_{t}^{p u b}}=\frac{(1-\varphi) g}{\varphi g+\rho} .
$$

Recalling that $\overline{H_{t}}=\left(H_{1 t}\right)^{p}\left(H_{2 t}\right)^{1-p}$ where $H_{1 t}=H_{t}^{p u b}$ and $H_{2 t}=H_{t}^{p r i}$, from equations (3), (6) and (8), we have

$$
g^{\varphi}(\varphi g+\rho)^{(1-\varphi)}=\phi\left[\frac{A(1+\widetilde{\delta})(1-\tau)(1-\varphi)}{\eta}\right]^{(1-\varphi)}\left(\frac{H_{2 t}}{H_{1 t}}\right)^{-p \varphi}
$$

and

$$
g=\phi A \tau\left(\frac{1+\widetilde{\delta}}{\eta}\right)\left[\frac{\rho+g}{\varphi g+\rho}\right]^{(1-p)}\left(\frac{H_{2 t}}{H_{1 t}}\right)^{(1-p)} .
$$

The two expressions for the growth rate and equation (23) make up a $3 \times 3$ system in relative human capital between the two sectors of education, $H_{t}^{p r i} / H_{t}^{p u b}=H_{2 t} / H_{1 t}$, growth rate, $g$, and the level of motivation, $\widetilde{\delta}$. As equation $(23)$ implies that $\left(H_{2 t} / H_{1 t}\right)=$ $\exp [(1-\varphi) g /(\varphi g+\rho)]$, simple manipulations of these expressions yield:

$$
(g)^{\varphi}(\varphi g+\rho)^{1-\varphi} \exp \left[p \varphi \frac{(1-\varphi) g}{\varphi g+\rho}\right]=\phi\left[\frac{A(1-\tau)(1-\varphi)(1+\widetilde{\delta})}{\eta}\right]^{1-\varphi}
$$

and

$$
\frac{g(\varphi g+\rho)^{1-p}}{(\rho+g)^{1-p}} \exp \left[-\frac{(1-p)(1-\varphi) g}{\varphi g+\rho}\right]=\frac{\phi A \tau}{\eta}(1+\widetilde{\delta}) .
$$

Eliminating the term $(1+\widetilde{\delta})$ between equations $(24)$ and $(25)$, we obtain:

$$
(g)^{\frac{\varphi}{1-\varphi}}(\rho+g)^{1-p}(\varphi g+\rho)^{p} \exp \left[\frac{g[p \varphi+(1-p)(1-\varphi)]}{\varphi g+\rho}\right]=g \phi^{\frac{\varphi}{1-\varphi}} \frac{(1-\tau)(1-\varphi)}{\tau} .
$$


This condition shows that a solution for $g>0$ (and thus for $\widetilde{\delta}>0$ and $H_{2 t} / H_{1 t}>1$ ) exists and is unique. That is, if the level of ambition of individuals is given by $\widetilde{\delta}$ : not only individuals are indifferent between private and public education but, also, a share $p$ of individuals chooses public education and a share $1-p$ opts for private education. Therefore, Proposition 1 follows.

\subsection{Steady-state in the mixed regime of education}

In the mixed regime of education, the less motivated opt for the public regime, while the more motivated opt for the private regime. Thus, equations (2) and (3) imply:

$$
g^{p u b}=\phi A \tau\left(\frac{1+\delta_{1}}{\eta}\right)^{p}\left(\frac{1+\delta_{2}}{\eta}\right)^{(1-p)}\left[\frac{\rho+g}{\varphi g+\rho}\right]^{(1-p)}(\widehat{H})^{-(1-p)},
$$

and

$$
g^{p r i}=\phi\left[\frac{A\left(1+\delta_{2}\right)(1-\tau) \varepsilon}{\left(1-\tau-\varepsilon^{*}\right) \eta}\right]^{1-\varphi}(\widehat{H})^{p \varphi} .
$$

Gathering the results depicted above allows us to determine the implicit value of the growth rate, $g^{*}$. We obtain

$$
\begin{aligned}
& \frac{g^{1+\frac{(1-p)}{p}}(\varphi g+\rho)^{(1-p) \frac{p \varphi+1-\varphi}{p \varphi}}}{(\rho+g)^{(1-p)}} \\
= & \phi^{1+\frac{(1-p)}{p \varphi}}\left(\frac{A}{\eta}\right)^{1+\frac{(1-p)(1-\varphi)}{p \varphi}}\left(1+\delta_{1}\right)^{p}\left(1+\delta_{2}\right)^{(1-p)\left(1+\frac{(1-\varphi)}{p \varphi}\right)} \tau[(1-\tau)(1-\varphi)]^{\frac{(1-p)(1-\varphi)}{p \varphi}},
\end{aligned}
$$

which is the solution given in equation (14) or

$$
\begin{aligned}
& \frac{g^{\varphi+\frac{p \varphi}{1-p}}(\varphi g+\rho)^{1-\varphi+p \varphi}}{(\rho+g)^{p \varphi}} \\
= & \phi^{1+\frac{p \varphi}{1-p}}\left(\frac{A}{\eta}\right)^{1-\varphi+\frac{p \varphi}{1-p}}(1-\varphi)^{1-\varphi}\left(1+\delta_{1}\right)^{p \frac{p \varphi}{1-p}}\left(1+\delta_{2}\right)^{1-\varphi+p \varphi}(1-\tau)^{1-\varphi}(\tau)^{\frac{p \varphi}{1-p}}
\end{aligned}
$$

depending on how we eliminate $\widehat{H}$. It can easily be checked that the two expressions are exactly the same. The second one is simply the first one to the power $p \varphi /(1-p)$. Simple algebra shows that a solution for $g^{*}=g^{p u b}=g^{p r i}$, with $g^{*}>0$, exists and is unique. The human capital ratio, the consumption ratio, and the quantities of labour follow directly from $(1),(2),(5),(7),(8)$.

\subsection{Outcome in a pure public and pure private regime}

We depict the outcome of the model in a pure public education regime and in a pure private regime of education, respectively. In the case of a pure public regime (case (a) in 
proposition 1 ), all individuals get the same level of human capital: $\widehat{H}^{*}=1$. The level of growth follows from (6) and is thus given by:

$$
g^{p u b}=\frac{\phi A \tau}{\eta}\left(1+\delta_{1}\right)^{p}\left(1+\delta_{2}\right)^{(1-p)} .
$$

Moreover, from $(1)$ where $\varepsilon^{*}=0$, the consumption ratio, $\widehat{C}^{*}$, is given by:

$$
\widehat{C}^{*}=\frac{C_{1 t}}{C_{2 t}}=\frac{L_{1}}{L_{2}}=\frac{1+\delta_{1}}{1+\delta_{2}} .
$$

Similarly, the growth rate in a pure private regime (part (b) of Proposition 1) is given by: $g^{p r i}=\phi\left(\varepsilon^{*} A L_{k}\right)^{1-\varphi}\left(\overline{H_{t}} / H_{k t}\right)^{\varphi}$ for all $k$, where we recall that $\varepsilon^{*}=\varepsilon_{1}^{*}=\varepsilon_{2}^{*}$ (see (13)). Taking the ratio of this equation for a typical individual 1 and a typical individual 2 , respectively, we obtain:

$$
\widehat{H}^{*}=\frac{H_{1 t}}{H_{2 t}}=\left(\frac{L_{1}}{L_{2}}\right)^{(1-\varphi) / \varphi}=\left(\frac{1+\delta_{1}}{1+\delta_{2}}\right)^{(1-\varphi) / \varphi} .
$$

Using (28), (8) and $\overline{H_{t}}=\left(H_{1 t}\right)^{p}\left(H_{2 t}\right)^{1-p}$, we obtain:

$$
\left(g^{p r i}\right)^{\varphi}\left(\varphi g^{p r i}+\rho\right)^{1-\varphi}=\phi\left[\frac{(1-\tau)(1-\varphi) A}{\eta}\right]^{1-\varphi}\left(1+\delta_{1}\right)^{p(1-\varphi)}\left(1+\delta_{2}\right)^{(1-p)(1-\varphi)},
$$

and

$$
\widehat{C}^{*}=\frac{C_{1 t}}{C_{2 t}}=\frac{H_{1 t}}{H_{2 t}} \frac{L_{1}}{L_{2}}=\left(\frac{1+\delta_{1}}{1+\delta_{2}}\right)^{1 / \varphi} .
$$

From the above results, we note that the pure public educational regime produces more growth than the pure private one at least if $\left(g^{p u b}=\right) \phi A \tau\left(1+\delta_{1}\right)^{p}\left(1+\delta_{2}\right)^{(1-p)} / \eta>$ $\phi\left[A\left(1+\delta_{1}\right)^{p}\left(1+\delta_{2}\right)^{(1-p)}(1-\tau)(1-\varphi) / \eta\right]^{1-\varphi}\left(>g^{p r i}\right)$ (see (26) and (29)), given that $\varphi g^{p r i}+\rho$ is likely to be lower than one. The following parameter changes increase the probability of the public regime growth rate being higher than the private regime rate: A higher tax rate, higher disutility of labour relative to the productivity parameter in output sector, $\eta / A$, and a lower level of status motivation and ambition. Moreover, the private-education regime produces always more income inequality than the public regime. Inequality becomes larger if the spillover effect in education (captured by $\varphi$ ) is low (see equations (27) and (30)).

\subsection{Transitional dynamics in the mixed regime of education}

We characterise the transitional dynamics of the model in a mixed regime of education. We assume that the choice of education regime is made once and for all at the beginning of the planning horizon $(t=0)$ for all individuals. We note that the growth rate of those in public education is given by: $g_{t}^{p u b}=\phi A \tau\left(L_{1 t}\right)^{p}\left(L_{2 t}\right)^{(1-p)}\left(\widehat{H}_{t}\right)^{p-1}$, where we used $\overline{H_{t}}=$ 
$\left(H_{1 t}\right)^{p}\left(H_{2 t}\right)^{1-p}$ and denoted by $\widehat{H}_{t} \equiv H_{1 t} / H_{2 t}$ which is a constant variable in steady state. Similarly, the growth rate in private education is given by: $g_{t}^{p r i}=\phi\left(\varepsilon_{2 t} A L_{2 t}\right)^{1-\varphi}\left(\widehat{H}_{t}\right)^{p \varphi}$. Then, denoting by $\omega_{t} \equiv \varepsilon_{2 t} /\left(1-\tau-\varepsilon_{2 t}\right)$ the relative amount of resources allocated to education and consumption (which is constant in steady state), we can manipulate the first order conditions of an individual opting for private education (see sub-section 3.2) with the law of motion of human capital in the private sector (3) to obtain:

$$
\begin{gathered}
\frac{\left(1+\delta_{2}\right)(1-\tau) \omega_{t}}{\eta}=\varepsilon_{2 t} L_{2 t}, \\
L_{2 t}=\frac{1+\delta_{2}}{\eta}\left(1+\omega_{t}\right), \\
\left(1+\delta_{2}\right)\left(\omega_{t}\right)^{\varphi}=\mu_{2 t}(1-\varphi) \phi\left(A \frac{\left(1+\delta_{2}\right)(1-\tau)}{\eta}\right)^{1-\varphi}\left(H_{1 t}\right)^{p \varphi}\left(H_{2 t}\right)^{1-p \varphi}, \\
(1-\varphi) g_{t}^{p r i}\left(\frac{1}{\omega_{t}}+1\right)=-\frac{\dot{\mu_{2 t}}}{\mu_{2 t}}+\rho .
\end{gathered}
$$

Manipulation of the above equations yields the following $2 \times 2$ system in $\left(\widehat{H}_{t}, \omega_{t}\right)$ :

$$
\begin{gathered}
\dot{\omega}_{t}=\omega_{t}\left\{\begin{array}{c}
\frac{\rho}{\varphi}+\frac{p \phi A \tau}{\eta}\left(1+\delta_{1}\right)^{p}\left(1+\delta_{2}\right)^{1-p}\left(1+\omega_{t}\right)^{(1-p)}\left(\widehat{H}_{t}\right)^{p-1} \\
+\phi\left[(1-p)-\frac{(1-\varphi)}{\varphi \omega_{t}}\right]\left[\frac{A\left(1+\delta_{2}\right)(1-\tau) \omega_{t}}{\eta}\right]^{1-\varphi}\left(\widehat{H}_{t}\right)^{p \varphi}
\end{array}\right\}, \\
\dot{\widehat{H}}_{t}=\widehat{H}_{t}\left\{\begin{array}{c}
\frac{\phi A \tau}{\eta}\left(1+\delta_{1}\right)^{p}\left(1+\delta_{2}\right)^{1-p}\left(1+\omega_{t}\right)^{(1-p)}\left(\widehat{H}_{t}\right)^{p-1} \\
-\phi\left[\frac{A\left(1+\delta_{2}\right)(1-\tau) \omega_{t}}{\eta}\right]^{1-\varphi}\left(\widehat{H}_{t}\right)^{p \varphi}
\end{array}\right\} .
\end{gathered}
$$

Taking a first order Taylor approximation of the above system around the steady state, we obtain:

$$
\left(\begin{array}{c}
\dot{\omega}_{t} / \omega_{t} \\
\dot{\widehat{H}}_{t} / \widehat{H}_{t}
\end{array}\right)=M\left(\begin{array}{c}
\omega_{t}-\omega^{*} \\
\widehat{H}_{t}-\widehat{H}^{*}
\end{array}\right)
$$

where " $*$ " indicates the steady-state value of any variable and we have used the steadystate property $g^{p u b}=g^{*}=\phi A \tau\left(1+\delta_{1}\right)^{p}\left(1+\delta_{2}\right)^{1-p}\left(1+\omega^{*}\right)^{(1-p)}\left(\widehat{H}^{*}\right)^{p-1} / \eta, g^{\text {pri }}=g^{*}=$ $\phi\left[A\left(1+\delta_{2}\right)(1-\tau) \omega^{*} / \eta\right]^{1-\varphi}\left(\widehat{H}^{*}\right)^{p \varphi}, \omega^{*}=(1-\varphi) g^{*} /\left(\varphi g^{*}+\rho\right)$. Lastly, the matrix $M$ is given by:

$$
M=\left(\begin{array}{cc}
\frac{p(1-p) g^{*}}{1+\omega^{*}}+\left(1-p+\frac{1}{\omega^{*}}\right) \frac{(1-\varphi) g^{*}}{\omega^{*}} & -\frac{p(1-\varphi) g^{*}}{\widehat{H}^{*}}\left(1-p+\frac{1}{\omega^{*}}\right) \\
{\left[(1-p) \omega^{*}-(1-\varphi)\left(1+\omega^{*}\right)\right] \frac{g^{*}}{\omega^{*}\left(1+\omega^{*}\right)}} & -g^{*}(1-p+p \varphi)
\end{array}\right) .
$$

Using $\omega^{*}=(1-\varphi) g^{*} /\left(\varphi g^{*}+\rho\right)$, we notice that $(1-p) \omega^{*}-(1-\varphi)\left(1+\omega^{*}\right)=$ $(1-\varphi)\left[(1-p) g^{*}-\left(\varphi g^{*}+\rho\right)-(1-\varphi) g^{*}\right] /\left(\varphi g^{*}+\rho\right)=-(1-\varphi)\left(p g^{*}+\rho\right) /\left(\varphi g^{*}+\rho\right)<0$. Using 
this information, direct inspection of the $M$ matrix reveals that its determinant is strictly negative meaning that its eigenvalues are real and have opposite signs. Hence, the unique steady-state equilibrium is a saddle point stable. The linearised system (31) is indeed characterised by one predetermined variable, $\widehat{H}_{t} \equiv H_{1 t} / H_{2 t}$, and one non predetermined (free to jump) variable, $\omega_{t} \equiv \varepsilon_{2 t} /\left(1-\tau-\varepsilon_{2 t}\right)$.

To refine our results and analyse the effects of a change in income tax both on impact and during the transition, we calibrate the model choosing benchmark parameter values (see third column of Table 1) for which, as observed in OECD countries, total expenditures as a percentage of GDP is roughly equal to five percent. By means of numerical methods, we show that for a wide range of values, reported in the fourth column of Table 1, the sign of eigenvalues remains identical.

Table 1: Baseline parameter values

\begin{tabular}{|l|c|c|c|}
\hline Description & Parameter & Benchmark values & Range \\
\hline Income tax & $\tau$ & $\tau=0.05$ & {$[0.01 ; 0.1]$} \\
\hline Human capital spill-over & $\varphi$ & $\varphi=0.1$ & {$[0.05 ; 0.7]$} \\
\hline $\begin{array}{l}\text { Skills parameter } \\
\text { in education }\end{array}$ & $\phi$ & $\phi=0.13$ & {$[0.02 ; 0.2]$} \\
\hline Share of individuals & $p$ & $p=0.7$ & {$[0.1 ; 0.9]$} \\
\hline Productivity in output sector & $A$ & $A=0.35$ & {$[0.05 ; 0.4]$} \\
\hline $\begin{array}{l}\text { Marginal disutility } \\
\text { of labour }\end{array}$ & $\eta$ & $\eta=1.3$ & {$[1 ; 5]$} \\
\hline Discount rate & $\rho$ & $\rho=0.05$ & {$[0.01 ; 0.07]$} \\
\hline Taste for status & $\delta_{1}<\delta_{2}$ & $\begin{array}{l}\delta_{1}=0 \\
\delta_{2}=0.05\end{array}$ & {$[0 ; 5]$} \\
\hline
\end{tabular}

Using the benchmark parameter values (third column in Table 1), we can compute the steady-state values of growth, relative human capital and consumption, the share of income individuals of group 2 spend in private education, the quantity of labour supplied by each type of individual and the threshold level of preference for status. Results are summarised in Table 2 .

Table 2: Steady-state outcome for the parameter values

\begin{tabular}{|c|c|c|c|c|c|c|}
\hline$g^{*}$ & $\widehat{H}^{*}$ & $\widehat{C}^{*}$ & $\varepsilon^{*}$ & $L_{1}^{*}$ & $L_{2}^{*}$ & $\widetilde{\delta}$ \\
\hline 0.00183107 & 0.932541 & 0.888134 & 0.0302051 & 0.769231 & 0.807692 & 0.0454302 \\
\hline
\end{tabular}

Denoting by $q_{i}, i=1,2$, the eigenvalues of $M$, simulation exercise leads to

$$
q_{1}=1.54481>0 ; \quad q_{2}=-0.00189961<0 .
$$

That is, as mentioned above, while one eigenvalue is positive, the other is negative. The stable arm corresponds to the eigenvector associated with the negative eigenvalue. As the corresponding matrix of eigenvectors is given by

$$
V=\left[\begin{array}{cc}
0.999484 & 0.0246064 \\
-0.0321101 & 0.999697
\end{array}\right]
$$


we conclude that, around the steady state, the slope of the saddle arm is positive. With this information in mind, we can analyse the impact of a change in income tax rate, $\tau$, on $\widehat{H}_{t} \equiv H_{1 t} / H_{2 t}$ and $\omega_{t} \equiv \varepsilon_{2 t} /\left(1-\tau-\varepsilon_{2 t}\right)$, both on impact and along the transition.

To proceed, we assume that the government decides to increase marginally and permanently the tax rate level, $\tau$. We restrict our attention to the case $\tau<\tau^{\text {max }}$ initially. This is indeed the most plausible scenario given that the "democratic" tax rate (either $\tau_{1}$ or $\tau_{2}$ ) necessarily falls below the growth maximizing one (see Proposition 5). Using the results derived previously and from the simulation exercise, we can infer that, on impact, $\omega_{t}$ jumps down on the new saddle path and, afterwards, sluggishly increases to its new steady state, i.e. approaches it from below.

Regarding the human capital ratio (state variable), there is no change on impact. Following the marginal increase of the tax rate, we can nevertheless deduce that it increases after impact. That is, along the transition, $\widehat{H}_{t}$ increases progressively to its new steady state and attains it from below. To summarise, when $\tau<\tau^{\max }$, following an increase in the tax rate level, both types of individuals experience an increase in their human capital growth. The difference is that the boost for the less motivated individuals surpasses the boost for the more motivated individuals. It thus results in a reduction of inequalities in human capital along the transition to the new steady state.

From the results above, it is straightforward to identify the effects of a change in $\tau$ on consumption, $C_{k t}$, on impact for both types of individuals. From the resource constraint (1): $C_{k t}=\left(1-\varepsilon_{k t}-\tau\right) A L_{k t} H_{k t}$, and equations (11), (12) and (13), it emerges that, on impact, consumption drops down for both types of individuals. Moreover, it is easy to check that, for those in public education, labour supply remains unchanged; for those in private education, in contrast, labour supply can either increase or decrease depending on whether the jump of $\omega_{t}$ is positive or negative. Therefore, we conclude that, although a marginal increase in the amount of resources devoted to public education induces welfare gains in the long run, its immediate effect (i.e. on impact) is always welfare reducing for the less motivated (poorer) individuals; the immediate impact on the welfare of the more motivated (richer) ones may be ambiguous.

\subsection{A more general technology in public education}

In this Appendix, we slightly modify the model by specifying a more general technol-

ogy of education in the public sector, such as: $\stackrel{\bullet}{H_{t}^{p u b}}=\phi\left(\tau \overline{Y_{t}}\right)^{1-\varphi}\left(\overline{H_{t}}\right)^{\varphi}$, where $\overline{Y_{t}}=$ $\left(Y_{1 t}\right)^{p}\left(Y_{2 t}\right)^{1-p}$. We will show that we would obtain the same results as in the simplified model used in the main text. For simplicity, we focus on the mixed regime of education in steady state. An important feature is that the behaviour of individuals described in the main text remains unchanged. The only difference is that, in steady state, the level of growth in public education (6) is now replaced by

$$
g=\phi(A)^{1-\varphi}(\tau)^{1-\varphi}\left(\frac{1+\delta_{1}}{\eta}\right)^{p(1-\varphi)}\left(\frac{1+\delta_{2}}{\eta}\right)^{(1-p)(1-\varphi)}\left[\frac{\rho+g}{\varphi g+\rho}\right]^{(1-p)(1-\varphi)}(\widehat{H})^{-(1-p)}
$$


where we have used $Y_{k t}=A L_{k t} H_{k t}, k=1,2$, with $L_{k t}$ given by (5) and (8) for individuals 1 and 2, respectively. Recalling that the level of growth in private education is given by $g=\phi\left\{A\left(1+\delta_{2}\right)(1-\tau) \varepsilon /[(1-\tau-\varepsilon) \eta]\right\}^{1-\varphi}(\widehat{H})^{p \varphi}$, we follow the same line of reasoning as before. Using (13), the growth rate in private education is given by:

$$
g=\phi\left[\frac{A\left(1+\delta_{2}\right)(1-\tau)(1-\varphi) g}{\eta(\varphi g+\rho)}\right]^{1-\varphi}(\widehat{H})^{p \varphi} .
$$

Eliminating $\widehat{H}$, we obtain:

$$
\begin{aligned}
\frac{(g)^{\varphi\left(1+\frac{p}{1-\varphi}\right)}(\varphi g+\rho)^{(1-\varphi)(1+p \varphi)}}{(\rho+g)^{(1-\varphi) p \varphi}}= & A^{(1-\varphi)\left(1+\frac{p \varphi}{1-p}\right)}(\phi)^{1+\frac{(1-\varphi) p \varphi}{1-p}}(1-\varphi)^{1-\varphi} \eta^{-(1-\varphi)\left(1+p \varphi+\frac{p^{2} \varphi}{1-p}\right)} \\
& \times\left(1+\delta_{2}\right)^{(1-\varphi)(1+p \varphi)}\left(1+\delta_{1}\right)^{\frac{p^{2} \varphi(1-\varphi)}{1-p}}(1-\tau)^{1-\varphi}(\tau)^{\frac{(1-\varphi) p \varphi}{1-p}} .
\end{aligned}
$$

Simple algebra allows us to show that the growth rate which is solution of this equation has the same properties as those described in the main text. In particular, we obtain an inverted U-shaped relation between the long run growth rate, $g$, and the tax rate, $\tau$.

\section{References}

Abel, A.B. (1990) "Asset Pricing under Habit Formation and Catching up with the Joneses" American Economic Review 80, 38-42.

Abel, A.B. (2005) "Optimal Taxation when Consumers Have Endogenous Benchmark Levels of Consumption" Review of Economic Studies 72, 21-42.

Aghion, P., E. Caroli and C. Garcia-Penalosa (1999) "Inequality and Economic Growth: The Perspective of the New Growth Theories" Journal of Economic Literature 37, 16151660 .

Alesina, A. and G. Tabellini (1990) "Voting on the Budget Deficit" American Economic Review 80, 37-49.

Alesina, A. and D. Rodrik (1994) "Distributive Politics and Economic Growth" Quarterly Journal of Economics 109, 465-490.

Alonso-Carrera, J. (2001) "More on the Dynamics in The Endogenous Growth Model with Human Capital" Investigaciones Economicas 25, 561-583.

Alvarez-Cuadrado, F., G. Monteiro and S.J. Turnovsky (2004) "Habit Formation, Catching up with the Joneses, and Economic Growth" Journal of Economic Growth 9, 47-80.

Anderson, D.S. (1988) "Values, Religion, Social Class and the Choice of Private School in Australia" International Journal of Educational Research 12, 351-373.

Ball, S.J. (1993) "Education Markets, Choice and Social Class: The Market as a Class Strategy in the UK and the USA." British Journal of Sociology of Education 14, 3-19. 
Ball, S.J. (1997) "On the Cusp: Parents Choosing between State and Private Schools in the UK: Action within an Economy of Symbolic Goods" International Journal of Inclusive Education 1, 1-17.

Ball, S.J., R. Bower and S. Gewirtz (1995) "Circuits of Schooling: A Sociological Exploration of Parental Choice of School in Social Class Contexts" Sociological Review 43, 52-78.

Barro, R.J (1990) "Government Spending in a Simple Model of Endogenous Growth" Journal of Political Economy 98, S103-S125.

Barro, R.J. (1991) "Economic Growth in a Cross Section of Countries" Quarterly Journal of Economics 106, 407-443.

Benabou, R. (2002) "Tax and Education Policy in a Heterogeneous-Agent Economy: What Levels of Redistribution" Econometrica 70, 481-517.

Bernal, J.L. (2005) "Parental Choice, Social Class and Market Forces: the Consequences of Privatization of Public Services in Education" Journal of Education Policy 20, 779-792.

Blankenau, W.F., N.B. Simpson and M. Tomljanovich (2007) "Public Education Expenditures, Taxation, and Growth: Linking Data to Theory" American Economic Review 97, 393-397.

Cardak, B.A. (2004) "Education Choice, Endogenous Growth and Income Distribution" Economica 71, 57-81.

Chatterjee, S. and A.K.M. Morshed (2011) "Infrastructure Provision and Macroeconomic Performance" Journal of Economic Dynamics and Control 35, 1288-1306.

Chen, H.J. (2005) "Educational Systems, Growth and Income Distribution: A Quantitative Study" Journal of Development Economics 76, 325-353.

Chen S. and M. Ravallion (1997) "What Can New Survey Data Tell Us about Recent Changes in Distribution and Poverty?" The World Bank Economic Review 11, 357-382.

Choudhary, A., P. Levine, P. McAdam and P. Welz (2007) "Relative Preferences, Happiness and Corrective Taxation" University of Surrey, mimeo.

Clark, A.E. and A.J. Oswald (1996) "Satisfaction and Comparison Income" Journal of Public Economics 61, 359-381.

Corneo, G. and O. Jeanne (1997) "On relative Wealth Effects and the Optimality of Growth" Economics letters 54, 87-92.

Corneo, G. and O. Jeanne (1999) "Pecuniary Emulation, Inequality and Growth" European Economic Review 43, 1665-1678.

Croix (de la), D. and M. Doepke (2004) "Public versus Private Education when Differential Fertility Matters" Journal of Development Economics 73, 607-629.

Croix (de la), D. and P. Michel, P. (2002) "A Theory of Economic Growth: Dynamics and Policy in Overlapping Generations" Cambridge University Press: Cambridge.

Deninger, K. and L. Squire (1996) "A New Data Set Measuring Income Inequality" The World Bank Economic Review 10, 565-591.

Devarajan, S., D. Xie and H. Zou (1998) "Should Public Capital be Subsidized or Provided?" Journal of Monetary Economics 41, 319-331. 
Fershtman, C., K.M. Murphy and Y. Weiss (1996) "Social Status, Education and Growth" Journal of Political Economy 104, 108-132.

Futagami, K., Y. Morita and A. Shibata (1993) "Dynamic Analysis of an Endogenous Growth Model with Public Capital" Scandinavian Journal of Economics 95, 607-625.

Futagami, K. and A. Shibata (1998) "Keeping one Step Ahead of the Joneses: Status, the Distribution of Wealth, and Long Run Growth" Journal of Economic Behavior \&3 Organization 36, 109-126.

Garcia-Penalosa, C. and S.J. Turnovsky (2006) "Growth and Income Inequality: A Canonical Model" Economic Theory 28, 25-49.

Glomm, G. and B. Ravikumar (1992) "Public versus Private Investment in Human Capital: Endogenous Growth and Income Inequality" Journal of Political Economy 4, 818-834.

Ghosh, S. and I.A. Mourmouras (2004) "Debt, Growth and Budgetary Regimes" Bulletin of Economic Research 56, 241-250.

Gradstein, M. and M. Justman (1997) "Democratic Choice of an Education System: Implications for Growth and Income Distribution" Journal of Economic Growth 2, 169183.

Grossman, M. (1972) "On the Concept of Health Capital and Demand for Health" Journal of Political Economy 80, 223-255.

Jones, C.I. and J.C. Williams (1998) "Measuring the Social Return to R\&D" Quaterly Journal of Economics 113, 1119-1135.

Jones, C.I. and J.C. Williams (2000) "Too Much of a Good Thing? The Economics of Investment in R\&D" Journal of Economic Growth 5, 65-85.

Lucas, R.E. (1988) "On the Mechanics of Economic Development" Journal of Monetary Economics 22, 3-42.

Mankiw, N.G., D. Romer and D.N. Weil (1992) "A Contribution to the Empirics of Economic growth" Quarterly Journal of Economics 107, 407-437.

Maurer, J. and A. Meier (2008) "Smooth it Like the Joneses? Estimating Peer-Group Effects in Intertemporal Consumption Choice" The Economic Journal 118, 454-476.

McBride, M. (2001) "Relative Income Effects on Subjective Well-Being in the CrossSection" Journal of Economic Behavior \& Organization 45, 251-278.

OECD (2008) "Education at a Glance" OECD indicators.

Partridge, M. (1997) "Is Inequality Harmful For Growth? Comment" American Economic Review 87, 1019-1032.

Persson, T. and G. Tabellini (1994) "Is Inequality Harmful for Growth?" American Economic Review 84, 600-621.

Pham, T.K.C. (2005) "Economic Growth and Status-Seeking through Personal Wealth" European Journal of Political Economy 21, 404-427.

Pollak, R.A. (1976) "Interdependent Preferences" American Economic Review 66, 309-320.

Saint-Paul, G. and T. Verdier (1993) "Education, Democracy and Growth" Journal of Development Economics 42, 399-407. 
Schultz, T.W. (1961) "Investment in Human Capital" American Economic Review 51, $1-17$.

Schultz, T.W. (1963) "The Economic Value of Education" Columbia University Press: New York.

Schultz, T.W. (1964) "Transforming Traditional Agriculture" Yale University Press: New Haven.

Sylwester, K. (2002) "Can Education Expenditures Reduce Income Inequality?" Economic Education Review 21, 43-52.

Tamura, R. (1991) "Income Convergence in an Endogenous Growth Model" Journal of Political Economy 99, 522-540.

Tournemaine, F. (2008) "Social Aspirations and Choice of Fertility: Why can Status Motive Reduce Per-Capita growth?" Journal of Population Economics 21, 49-66.

Tournemaine, F. and C. Tsoukis (2008) "Relative Consumption, Relative Wealth and Growth" Economics Letters 100, 314-316.

Tournemaine, F. and C. Tsoukis (2009) "Status Jobs, Human Capital and Growth: The Effects of Heterogeneity" Oxford Economic Papers 61, 467-493.

Tournemaine, F. and C. Tsoukis (2010) "Gain versus Pain from Status and Ambition: Effects on Growth and Inequality" Journal of Socio-Economics 39, 286-294.

Tsoukis, C. (2007) "Keeping up with the Joneses, Growth, and Distribution" Scottish Journal of Political Economy 54, 575-600.

Tsoukis, C. and N.J. Miller (2003) "Public Services and Endogenous Growth" Journal of Policy Modeling 25, 297-307.

Tsoukis, C. and F. Tournemaine (2012) "Status in a canonical macro model: labour supply, growth, and inequality" The Manchester School, forthcoming.

Turnovsky, S.J. (1996) "Methods of Macroeconomic Dynamics" Boston, MA: MIT Press.

Vandycke, N. (2001) "Access to Education for the Poor in Europe and Central Asia" World Bank Technical paper No 511, IBRD, Washington DC.

van Zon, A. and J. Muysken (2001) "Health and Endogenous Growth" Journal of Health Economics 20, 169-185.

Weil, D. (2005) "Accounting for the Effect of Health on Economic Growth" NBER wp. 11455.

World Bank (1993) "The East Asian Miracle. Economic Growth and Public Policy" World Bank. Policy Research Department Washington, D.C.

Zhang, J. (1996) "Optimal Public Investments in Education and Endogenous Growth" Scandinavian Journal of Economics 98, 387-404. 